\title{
MATERIAIS E BRINQUEDOS INFANTIS: REFLEXÕES ACERCA DA ATUAÇÃO DO DESIGNER PARA UM CONSUMO SUSTENTÁVEL
}

\author{
Taciana Lucio Hummel \\ Universidade do Estado de Minas Gerais \\ tacianahummel@hotmail.com \\ Leililene Antunes Soares \\ Universidade do Estado de Minas Gerais \\ Leililene@gmail.com \\ Juliana Martins de Souza \\ Universidade do Estado de Minas Gerais \\ julianadesigndeproduto@gmail.com
}

Resumo: $O$ estudo identifica os aspectos materiais considerados pelas famílias no consumo sustentável de brinquedos infantis. Para tanto, realizou-se uma pesquisa descritiva, qualitativa, tendo como unidade de análise 30 famílias de classes sociais distintas A, B e C; escolhidas pela amostragem estratificada com critério de inclusão possuir como membro criança na faixa etária de seis a oito anos. As informações foram coletadas por meio de questionário nas unidades familiares. Os dados foram operacionalizados através de tabulação manual e mecânica, para fins de construção de perfis e análise descritiva do conteúdo dos mesmos, discussão e fundamentação teórica com base nas respectivas referências bibliográficas. Constatou-se que os materiais influenciam na tomada de decisão, sendo critério relevante no momento da compra. Os designers desempenham importante papel na sociedade ao projetar diversos objetos, para tanto será exposto reflexões sobre as atuações do designer na concepção de produtos infantis integrando-os ao desenvolvimento sustentável.

Palavras-chave: Brinquedos infantis, sustentabilidade, designer, material.

Abstract: This study identifies the material aspects considered by families in sustainable consumption of children's toys. Therefore, there was a descriptive, qualitative research, with the analysis unit 30 families from different social classes $A, B$ and $C$; chosen by stratified sampling with inclusion criteria have as a child member in the age group of six to eight years. The information was collected through a questionnaire on family units. The data were operationalized through manual and mechanical tab for profiles construction purposes and descriptive analysis of the content thereof, discussion and theoretical foundation based on their references. It was found that the material influence the decision making, being relevant 
criteria at the time of purchase. The designers play an important role in society when designing various objects, for both will be exposed reflections on the performances of the designer in the design of children's products integrating them to sustainable development.

Keywords: Children toys, sustainability, designer, material.

\section{INTRODUÇÃO}

Com a emergência de novas forças produtivas e a reestruturação de um sistema econômico de alta produtividade, o consumo surge como conduta ativa e coletiva e o indivíduo assume neste sistema o papel de consumidor.

O consumo tornou-se um objeto de investigação mais complexo a partir da incorporação de novas perspectivas teóricas. Este termo pode ser definido como a seleção, compra e uso de bens e serviços. Diz-se ainda que consumo é a aquisição e utilização de bens e serviços diretamente para satisfazer desejos (SILVA, 2002).

Dentro do grupo familiar, o consumo de produtos para as crianças merece destaque, tendo em vista que atualmente os pais consideram as opiniões e ideias das crianças a respeito do que consumir. Ademais, segundo Gade (2008) a criança constitui cerca de um terço da população, representando um mercado de consumo respeitável, que por sua vez, tem capacidade de distinguir os produtos, as marcas e serem influenciados pela mídia.

O aumento desenfreado do consumo, com a obsolescência programada, as práticas de desperdício inconsciente e compras desnecessárias se tornam fatores críticos do tipo de consumo atual, sendo então de suma importância o desenvolvimento de estudos para fortalecer a ideia de sustentabilidade e novos hábitos de consumo.

Neste contexto, o objetivo do presente estudo é identificar os aspectos materiais considerados pelas famílias no consumo sustentável de brinquedos infantis, além de explorara maneira de como o designer, por meio de suas escolhas projetuais, pode ajudarna questão da sustentabilidade.

\section{FUNDAMENTAÇÃO TEÓRICA}

Manzini e Vezzoli (2002) caracterizam a dimensão ambiental da sustentabilidade segundo condições, as quais, em níveis regionais e planetários, as atividades humanas não devem interferir nos ciclos naturais. Nas palavras de Kazazian (2005, p.7), "vivemos uma 'idade' em que se impõe o desenvolvimento sustentável, estando ao nosso alcance imaginar soluções que favoreçam a prosperidade sem que isso implique regredir em qualquer setor dos sistemas econômico ou natural".

Com o avanço da ciência e da tecnologia, surgiram e continuam surgindo inúmeros novos materiais. Existem aproximadamente 100 mil materiais, essa gama permite que o design seja inovador a partir da exploração imaginativa dos novos e aprimorados materiais. Este número tende a aumentar principalmente pelo fato de que as pessoas estão mais conscientes das questões relacionadas à seleção de 
materiais em razão do surgimento do conceito de sustentabilidade (ASHBY e JOHNSON, 2010 apud CALEGARI; OLIVEIRA).

Santos (2009, p.13) apresenta que para atingir a sustentabilidade de fato é preciso reposicionar pensamentos e costumes quanto ao consumo e aprendizado sobre a natureza. Uma cartilha apresentada pelo Instituo Alana (2013), afirma que "a base da sustentabilidade repousa na capacidade de uma nação promover o bem-estar desta e das futuras gerações", e para isso é necessário respeitar os recursos naturais disponíveis, consumindo-os de maneira a respeitar seus limites, não esquecendo também de reduzir o lixo gerado.

No contexto atual, destaca-se a importância de investir na promoção de uma cultura de sustentabilidade entre os jovens, desenvolvendo processos e estratégias de interação e promovendo a construção de contextos para transformação. É especialmente em relação às novas gerações que a transição rumo a modos de vida mais saudáveis, integrados e sustentáveis mostra-se fundamental (MOUCHREK; KRUCKEN, 2014).

Assim, a educação ambiental é colocada como um requisito para se alcançar o desenvolvimento sustentável, sendo considerado um aprendizado na qual ajuda a adquirir competências necessárias para se aprender a lidar de maneira eficiente na solução e preservação dos problemas ambientais (CAVALCANTE et al., 2012).

As crianças são a porta de entrada para um futuro mais sustentável. Se aprenderem a agir e a consumir com consciência serão importantes transformadores sociais (ALANA, 2013). Isso porque influenciam a tomada de decisão do consumo nas unidades familiares.

O caminho para o desenvolvimento sustentável deve ser trilhado já na infância, para que desde pequenas as crianças adquiram conhecimento e comportamentos, quanto as suas ações para com o meio em que vivem, aprendendo a respeitarem e cuidarem do meio ambiente (ALANA, 2013).

Neste contexto, há a necessidade de propor mudanças de estilo de vida e cultura, objetivando mudanças nos modos de consumo. Neste sentido, que o papel do design pode vir a contribuir, tendo em vista que a aplicação dos seus conhecimentos devem superar as características estéticas e funcionais e, interferir nos fenômenos socioambientais e econômicos (MORELLI, 2002).

O designer tem como uma de suas incumbências transformar os materiais e tecnologias existentes em objetos de uso, ou seja, a materialização do contato do homem com o meio, através da forma tridimensional-física do objeto. O conhecimento dos processos de fabricação e dos materiais é indispensável para que o designer consiga materializar um projeto conceitual ou ideológico com intuito de compreender a importância dos materiais para a civilização humana (CÂNDIDO, 2012).

A área de design constitui um potencial campo de inovação criativa e suporte para iniciativas promissoras de promoção de sustentabilidade, oferecendo competências e habilidades, uma metodologia projetual e um olhar diferenciado (MOUCHREK; KRUCKEN, 2014).

Ainda para as autoras, a transição em direção a uma cultura e um estilo de vida sustentáveis, emergem potencialidades e interfaces de ação do design, indicando que conceitos e ferramentas de design podem oferecer suporte e caminhos criativos para práticas inovadoras. 
Assim, colocando em ato descontinuidades locais promissoras e participando no desenvolvimento de um bem-estar ativo - em que as capacidades de sensibilidade, competência e espírito de iniciativa tem um importante papel -, o design pode contribuir para mudanças sistêmicas efetivas. Em síntese, cabe ao designer participar ativa e positivamente no desenvolvimento de soluções sustentáveis, em diversos campos (MANZINI, 2008).

Os materiais sempre estiveram presentes na evolução do homem, os materiais eram utilizados com o intuito de ajudar na sobrevivência humana, mas, ao longo do tempo, essa prática foi sendo incorporada a todas as culturas, tornando-se substância de realização em todas as esferas das civilizações. Basta lembrar que, as diversas eras pela qual o homem passou, são caracterizadas pelo grau de desenvolvimento e utilização dos materiais: idade da pedra, idade do bronze, idade do ferro (CÂNDIDO, 2012).

O design de brinquedos contemporâneo está intimamente ligado ao conceito moderno de infância, bem como à percepção que temos quanto as crianças. Sabe-se que esta relação vem sendo construída ao decorrer do tempo e é fruto de fatores, sociais, econômicos, tecnológicos e culturais (COTRIM, 2015).

A partir de 1900 os brinquedos passaram a estimular uma nova forma de conexão com os usuários, mais profunda e visceral. Contagiado pelo sentimento de progresso e reconstrução, o design de brinquedos se propôs a construir o futuro com um bloco de cada vez. E, ao perceber o potencial das novas mídias, se apropriou das telas e inverteu o jogo, passando a criar fantasias que evoluíram em narrativas e estimularam o consumo (CONTRIM, 2015).

\section{METODOLOGIA}

O presente estudo é delineado por uma abordagem qualitativa, embasada nos aportes teóricos de Ludke e André (1986, p.18), por considerarem que "o estudo qualitativo desenvolve-se numa situação natural, é rico em dados descritivos, tem um plano aberto e flexível e focaliza a realidade de forma complexa e contextualizada".

Optou-se por essa abordagem, por considerarmos que o aporte instrumental metodológico de natureza qualitativa propicia uma dimensão mais ampla das questões propostas e de sua análise, bem como um aprofundamento no mundo dos significados das ações, das relações, fatores que não são apreendidos ou percebidos em dados puramente estatísticos.

Essa abordagem, portanto, possibilitará a descrição das particularidades do objeto, buscando aprender a complexidade do fenômeno estudado em seu contexto. Este estudo envolveu a obtenção de dados verbais e processos interativos por contato direto da pesquisadora com a situação estudada, procurando entender os fenômenos segundo a perspectiva dos sujeitos; o que implica certo grau de subjetividade.

Este estudo tem como unidade de análise 30 famílias de classes sociais distintas A, B e C;com critério de inclusão possuir como membro criança na faixa etária de seis a oito anos.

A escolha das famílias para a aplicação da pesquisa foi pela técnica de amostragem estratificada, uma vez que a estratificação é indicada para população irregular e heterogênea. Sendo selecionadas assim, as 30 famílias, elencadas segundo 
os dados obtidos por meio da Pesquisa Nacional por Amostra de Domicílio (Pnad) em 2015 com base na classificação econômica familiar, em classe A, B e C.

Após todos os sujeitos assinarem um termo de consentimento esclarecendo o objetivo e justificativa da pesquisa, as informações foram coletadas por meio de questionários com os pais e/ou responsáveis pelas crianças.

Os dados foram operacionalizados através de tabulação manual e mecânica, para fins de construção de perfis e análise descritiva do conteúdo dos mesmos, discussão e fundamentação teórica com base nas respectivas referências bibliográficas.

\section{RESULTADOS E DISCUSSÃO}

A frequência na compra dos brinquedos, como de qualquer tipo de produto, reflete o caráter consumista da família. Para Portilho (2010), o consumismo não é causado apenas pela grande produção, mas também pela cultura e "necessidade criada" pela sociedade de sempre consumir. Isto é reflexo do tipo de sociedade em que se vive, as mais simples costumam consumir bens e serviços necessários para sua sobrevivência em primeiro lugar, diferentemente das sociedades mais sofisticadas, onde o consumo assume um carácter simbólico mais presente, veiculado aos produtos e serviços adquiridos (PAULA, 2011, p.10).

Durante a escolha de brinquedos, os educadores e pais de crianças, incentivam a compra daqueles que possuem as características visuais relevantes (cores vivas, brilho, formas chamativas, contrastes, design), o que acaba se tornando comum na percepção visual dos usuários, por isso, boa parte dos brinquedos possui características visuais predominantes para atender à necessidade e preferência de mercado (KAMISAKI, 2011).

A Organização para a Cooperação Econômica e Desenvolvimento (OECD, 2002) orienta que o consumidor deve ter a consciência de que a compra é um ato de cidadania, no qual é necessário avaliar o produto desde a seleção - incluindo o uso e a manutenção - até o destino final. Isto significa valorizar empresas que procuram ser socialmente responsáveis, se preocupando com o impacto de sua produção e do consumo sobre o meio ambiente e buscando a melhor relação entre preço, qualidade e atitude social (CAVALCANTI, 2011).

A renda é um dos principais fatores que explicam o comportamento doconsumidor, pois o indivíduo tende a adequar, pelo menos à longo prazo, seus gastos à sua restrição orçamentária. $O$ estilo de vida que os consumidores adotam pode ser explicado por vários fatores, um deles seria a aspiração e/ou a cristalização do status que envolvem o posicionamentoobjetivo ou subjetivo em uma classe social influenciam bastante.

Nos dados obtidos por meio da Pesquisa Nacional por Amostra de Domicílio (Pnad) em 2015, com base na classificação econômica familiar, as famílias elencadas como $\mathrm{A} 1$ e $\mathrm{A} 2$, ou seja, o topo da pirâmide da riqueza brasileira representam $6 \%$ da população, possuem renda média mensal de 16,5 salários mínimos; a classe B1 e B2, representam $36 \%$ da população com renda mensal de 6,8 salários mínimos; a classe $C$ representando $47 \%$ da população com renda mensal de 2,5 salários mínimos; a classe $D$ representando $10 \%$ da população com renda mensal de 1,3 salários mínimos e a classe E, representando $1 \%$ da população, renda mensal de 0,8 salários mínimos (IBGE, 2015). 
Importa destacar que neste estudo, com amostra de 30 famílias, considerando a estratificação do Pnad (2015)10 famílias representam a classe A, 10 a classe B e 10 a classe $\mathrm{C}$.

O tipo de material utilizado na fabricação dos brinquedos sempre é considerado pelas famílias da Classe A. O material que compõe é considerado na maioria das vezes pela Classe C, representando $70 \%$ dos entrevistados. Dentre as famílias da Classe B 50\% declaram levar em consideração o tipo de material, as demais (50\%) não (Figura 1).

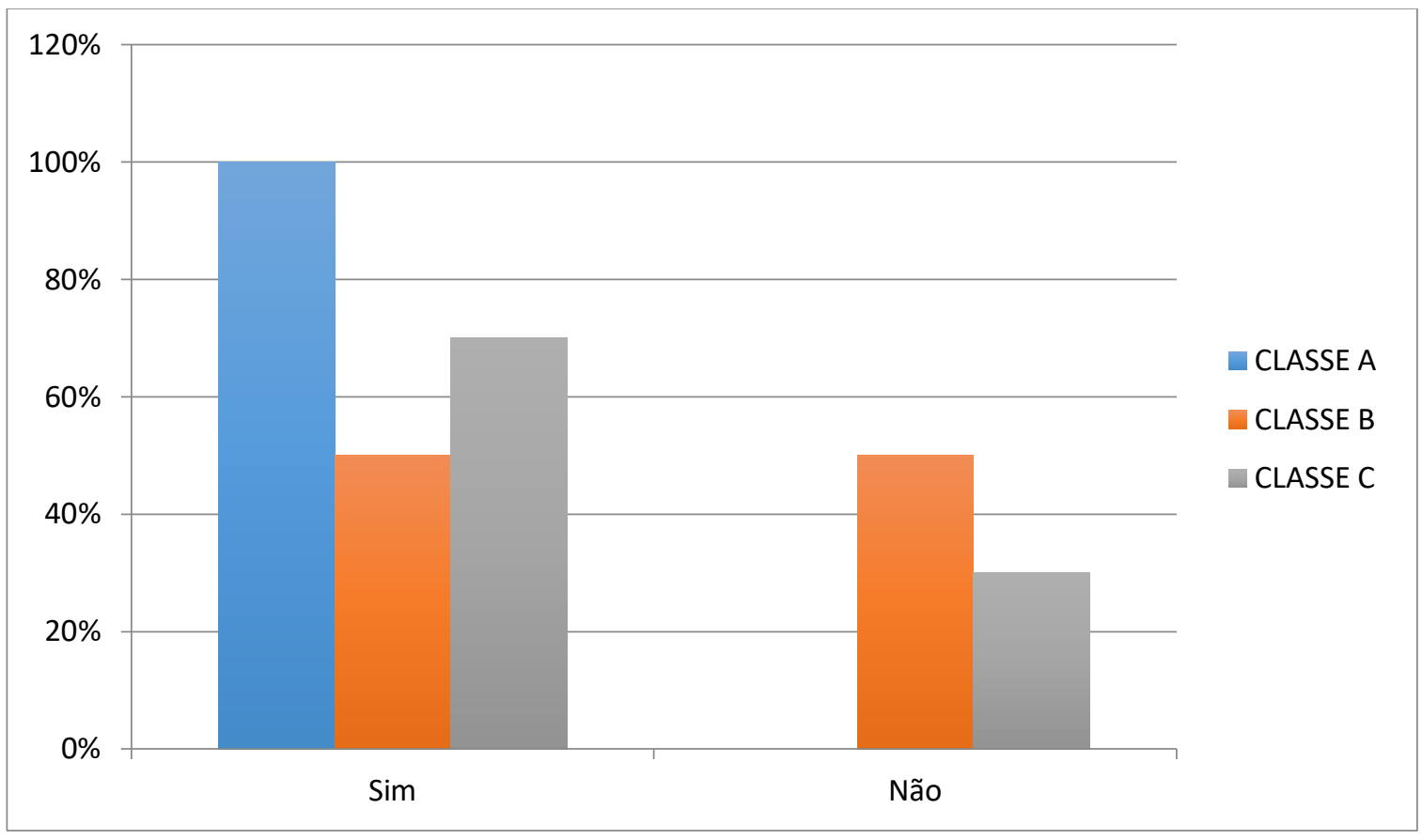

Figura 1 - Famílias que se preocupam com o material utilizado na fabricação de brinquedos. Fonte: Dados da pesquisa.

Os materiais sólidos têm sido agrupados em três classificações básicas: metais, cerâmicos e polímeros. Essa classificação está baseada principalmente na composição química e na estrutura atômica, na qual a maioria dos materiais se encaixa em agrupamentos distintos, embora existam alguns materiais intermediários (CALLISTER, 2002).

No início da utilização dos materiais (100.000 AC), o homem era dependente somente de materiais naturais. Ao longo da evolução humana da descoberta de novos materiais e novas necessidades de consumo, o homem foi sendo levado a utilizar materiais altamente dependentes de recursos não-renováveis. Essa atual dependência por materiais não-renováveis, dificilmente retornará a patamares mínimos, visto que, a evolução humana ao longo dos anos, teve como alicerce o desenvolvimento destes materiais, provenientes de recursos não-renováveis, como por exemplo, o petróleo (CÂNDIDO, 2012).

Todas as famílias, Classe A, B e C, relatam que o material predominante nos brinquedos adquiridos é o plástico (Figura 2). 


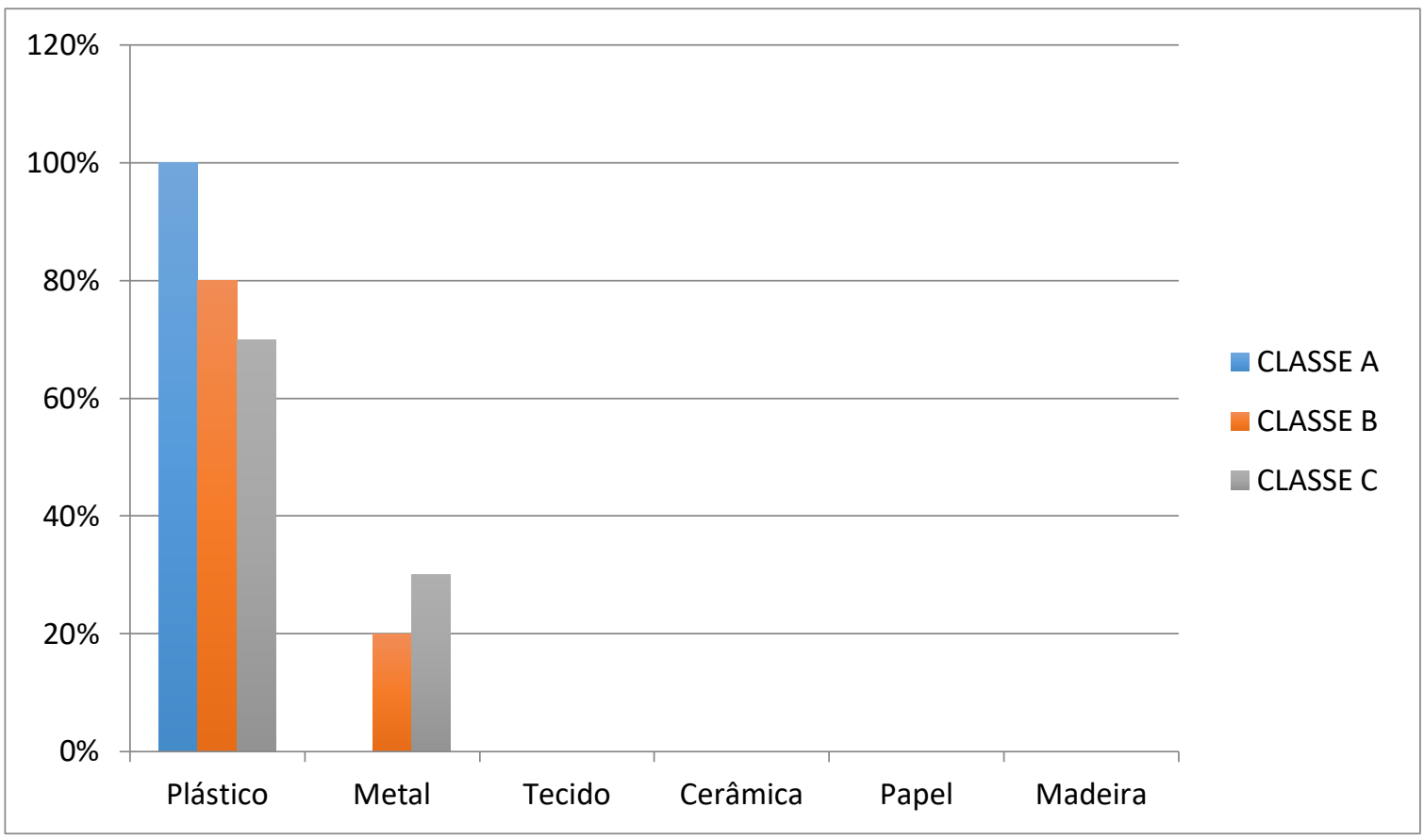

Figura 2- Material predominante nos brinquedos comprados para as crianças

Fonte: Dados da pesquisa

Para Callister (2002) os materiais metálicos são normalmente combinações de elementos metálicos. Os polímeros compreendem os materiais comuns de plástico e borracha. Muitos deles são compostos orgânicos que têm sua química baseada no carbono, no hidrogênio e em outros elementos não-metálicos.

Podemos dizer que o surgimento dos polímeros para uso mercadológico proporcionou um caráter radical na inovação dos produtos, o que modificou completamente as práticas técnico-científicas e sociais. Dentre estas inúmeras possibilidades, a utilização de um determinado material ocorre desde que suas propriedades físicas, mecânicas, químicas, seu custo e sua disponibilidade no mercado possam atender as especificações do projeto (CÂNDIDO, 2012).

Nota-se (figura 3) que na grande maioria apenas alguns dos brinquedos adquiridos pela classe $A$ podem ser reciclados, assim como a grande maioria dos brinquedos adquiridos pela classe $B$ e $C$ também podem ser reciclados. 


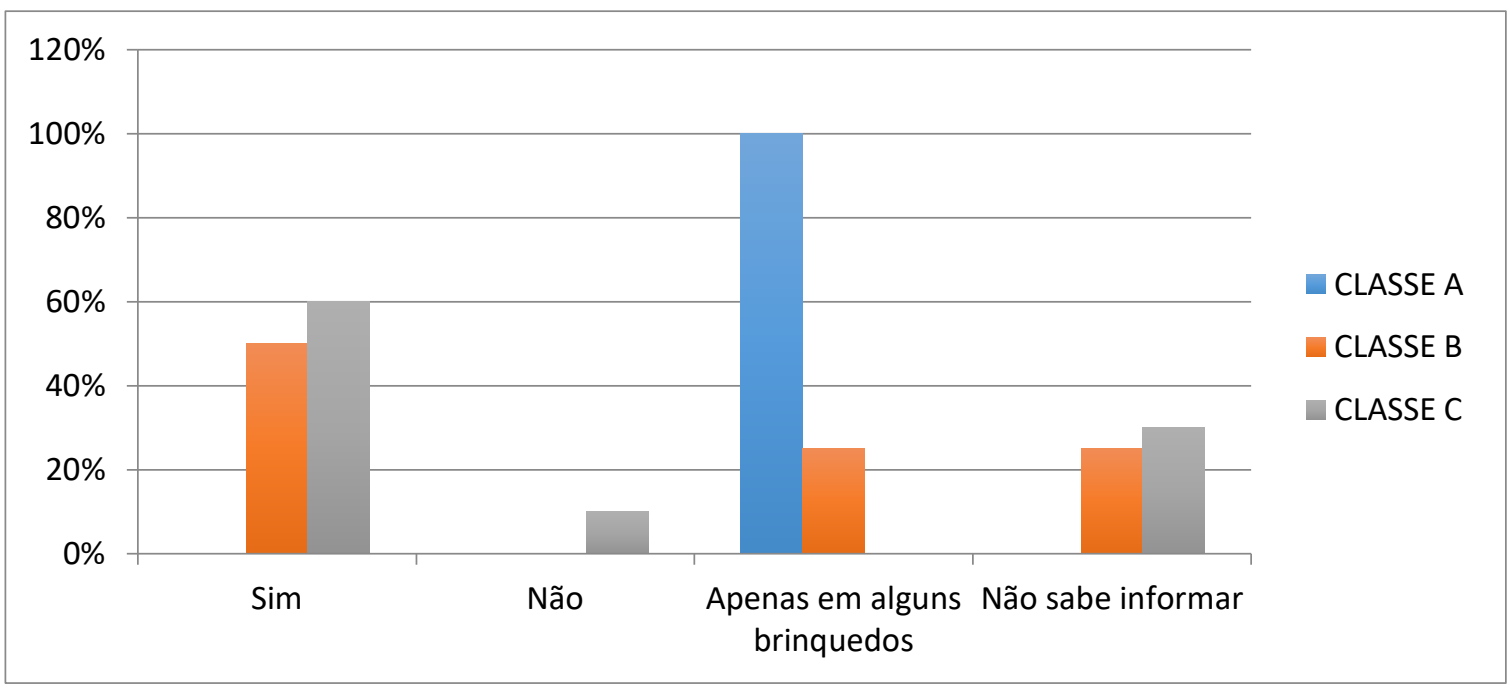

Figura 3 - Materiais que permitem a reciclagem dos brinquedos

Fonte: Dados da pesquisa.

O processo inovador na área do design é potencializado quando existe o interesse e a apropriação comercial de invenções ou a introdução deaperfeiçoamentos nos bens e/ou serviços utilizados pela sociedade. Neste sentido, a evolução dos materiais propiciou ao designer o aumento no número de oportunidades e da quebra de paradigmas da utilização de materiais. Porém, as informações sobre a reciclabilidade destes materiais não tiveram a mesma evolução, gerando com isso uma carência de informações técnicas sobre esse tema (CÂNDIDO, 2012).

Considerando, apenas a dimensão ambiental na busca do desenvolvimento sustentável, se faz necessário a aplicação de requisitos para o desenvolvimento de produtos e serviços sustentáveis, que em linhas gerais, estabelecem a minimização de recursos, a extensão do ciclo de vida dos materiais, a otimização do ciclo de vida dos produtos, a seleção de recursos de baixo impacto e facilidade de montagem e desmontagem (SANTOS, 2009).

Constatou-se que grande parte dos brinquedos não são descartados, destinamse para doações aumentando o ciclo de vida do produto, porém outra parte desses brinquedos são destinados ao lixo comum e não sendo encaminhados para centros de reciclagem, por exemplo (Figura 4). 


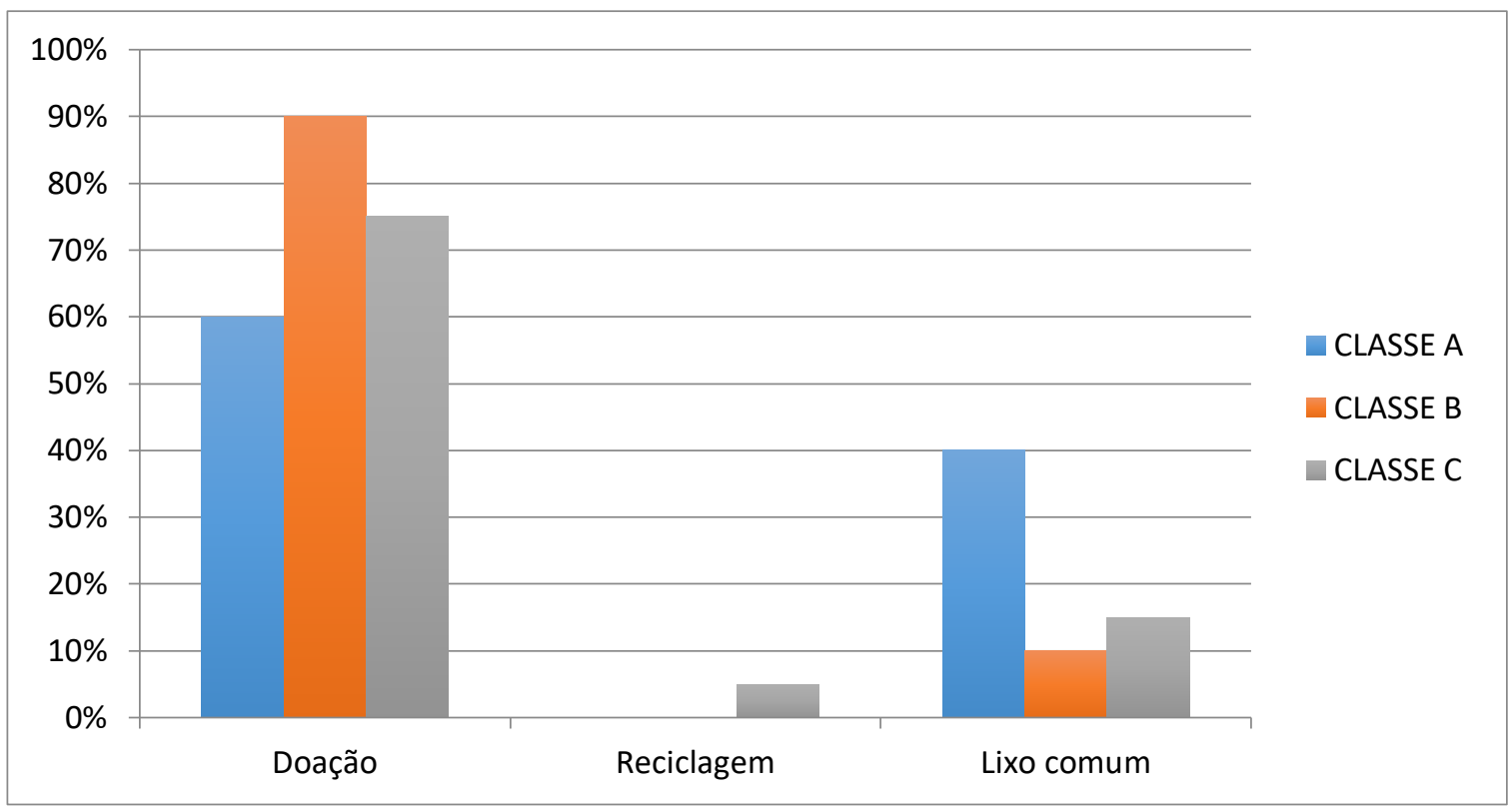

Figura 4 - Descarte do brinquedo pela família

Fonte: Dados da pesquisa.

Torna-se claro que não basta desenvolver um produto eficiente, bem aceito pelo usuário e de baixo custo de fabricação. O desenvolvimento deve levar em consideração a responsabilidade ambiental envolvida em todo o processo do projeto, de fabricação e reciclagem. Porém, em vários casos os projetistas não possuem, ou são raras, as informações sobre um determinado material no que tange a sua reciclabilidade, sendo que o predomínio é de informações físicas, químicas ou mecânicas do material a ser utilizado (CÂNDIDO, 2012).

Assim, o designer deve agir de forma social e ambientalmente responsável em todas as suas atividades produtivas. Nesse sentido, responsabilidade socioambiental e empresarial significa adotar princípios e assumir práticas que vão além da legislação, contribuindo realmente para a construção de uma sociedade consciente.

\section{CONCLUSÃO}

Repensar a utilização dos materiais é uma das possíveis e mais eficientes formas para se atingir a sustentabilidade. É importante frisar que a sustentabilidade é diretamente ligada a mudança de comportamento de cada uma das partes, usuário e profissional, cabe ao consumidor controlar consumo excessivo dos brinquedos destinados as crianças, assim como compreender os malefícios advindos dos materiais empregados neles e o destino na qual será dado ao brinquedo.

Como incentivo a essa nova conduta e mudança de comportamento, torna-se importante induzir e educar a criança a tomar novas atitudes, pois esses aprendizados serão levados para a vida e que futuramente trarão resultados benéficos para o objetivo principal do tema abordado, a sustentabilidade. É da competência que o profissional, designer, se posicione em como sua conduta contribuindo para um meio ambiente melhor, mantendo a boa qualidade do serviço e sempre procurando meios sustentáveis e produtivos para tal finalidade. É fato que não se pode resolver todos os problemas, e que os produtos desenvolvidos concluirão em algum tipo de resíduo, mas é preciso que o designer contribua para que a cultura da simples compra e descarte 
dos produtos seja repensada e ofereça novas formas de posicionamento a serem tomadas pelos consumidores. $O$ designer, ligado às questões de viabilidade produtiva, precisa se preocupar na seleção de materiais duradouros e recicláveis, mesmo que estes sejam uma escolha mais cara, é imprescindível para diminuir o nível de desperdício e lixo industrial, bem como a comunicação quanto ao descarte, reutilização e impactos dos mesmos.

A sociedade necessita de profissionais de design competentes, conscientes por trabalhar para um consumo sustentável promovendo reflexões acerca dos impactos do consumismo exacerbado sobre os recursos naturais.

Importa destacar que pesquisas no âmbito do consumo, infância e sustentabilidade são pouco contempladas pela área do design, tornando relevantes outras pesquisas nesse contexto.

\section{REFERÊNCIAS}

ALANA Instituto; Ministério do meio ambiente. Consumismo infantil: na contramão da sustentabilidade. 2013.

CALLISTER, W. D. Ciência e Engenharia de Materiais: Uma Introdução. 5ed. São Paulo: LTC, 2002.

CÂNDIDO, L. H. A. Compatibilidade de materiais x Elementos de fixação. Porto Alegre, RS: Brasil, 2012.

CAVALCANTI, D. C. Consumo sustentável. São Paulo: SMA/CPLA, 2011.

CAVALCANTE, A. L. et al. Design para sustentabilidade: um conceito interdisciplinar em construção. Projética, Londrina: v.3, n.1, jul. 2012.

COTRIM, M de A. P. Brincando com monstros:Design, infância e cultura pop. Belo Horizonte: UEMG. (Mestrado em Design) - UNIVERSIDADE DO ESTADO DE MINAS GERAIS, Belo Horizonte, 2015.

GADE, C. Psicologia do consumidor. Rio de Janeiro: EPU. 2008.

KAZAZIAN, T. Haverá a idade das coisas leves: design e desenvolvimento sustentável. São Paulo: Editora Senac, 2005.

LUDKE, M.; ANDRÉ, M. E. D. A. Pesquisa em educação: abordagens qualitativas. São Paulo: EPU, 1996.

MANZINI, E.; VEZZOLI, C. O desenvolvimento de produtos sustentáveis: os requisitos ambientais dos produtos industriais. São Paulo: Edusp, 2002.

MOUCHREK; KRUCKEN. Laboratório de design, cocriação e sustentabilidade:

uma iniciativa no ensino de Design. 11ㅇ P\&D DESIGN. Gramado, RS: 2014.

PAULA, E. C. de. O consumo infantil de brinquedos. Viçosa: UFV, 2011. (Graduação em Pedagogia) - UNIVERSIDADE FEDERAL DE VIÇOSA, Viçosa, 2011.

SANTOS, A. M. Criança e propaganda: tendência a uma infância comprada. Laboratório de Estudos Contemporâneos. Polêmica Revista Eletrônica, 2009. Universidade do Estado do Rio de Janeiro.

SILVA, N. M. Educação do Consumidor. Viçosa, UFV, 2002. 